Supporting Information for

\title{
Enhanced Sensitivity for Electrochemical Detection Using Screen-Printed Diamond Electrodes via the Random Microelectrode Array Effect
}

Takeshi Kondo, ${ }^{*, \dagger, \neq, \S}$ Ikuto Udagawa, ${ }^{\dagger}$ Tatsuo Aikawa, ${ }^{\dagger}$ Hironori Sakamoto, $^{\dagger}$ Isao Shitanda, ${ }^{\dagger, \ddagger}$ Yoshinao Hoshi, ${ }^{\dagger}$ Masayuki Itagaki ${ }^{\dagger, \ddagger}$ and Makoto Yuasa ${ }^{\dagger, \neq, \S}$

${ }^{\dagger}$ Department of Pure and Applied Chemistry, Faculty of Science and Technology, Tokyo University of Science, 2641 Yamazaki, Noda, Chiba 278-8510, Japan

${ }^{\star}$ Research Institute for Science and Technology, Tokyo University of Science, 2641 Yamazaki, Noda, Chiba 278-8510, Japan

§ ACT-C/JST, 4-1-8 Honcho, Kawaguchi, Saitama 333-0012, Japan

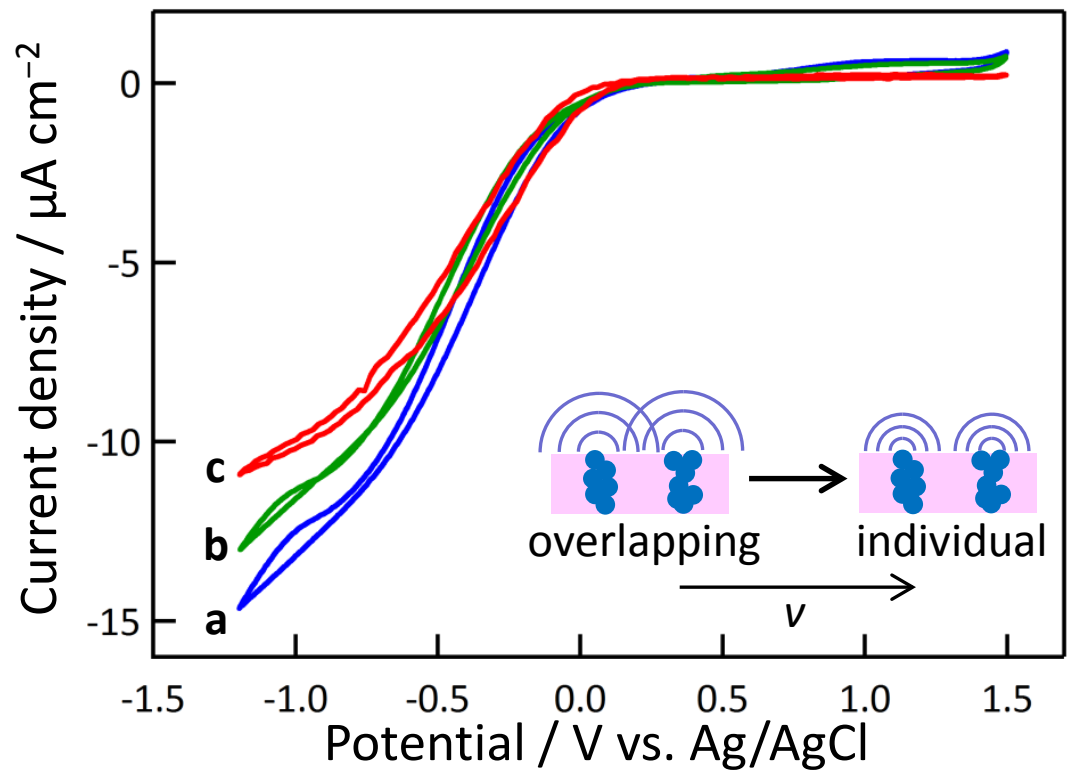

Figure S1. CVs for $0.5 \mathrm{mM} \mathrm{K}_{3} \mathrm{Fe}(\mathrm{CN})_{6}$ in $0.5 \mathrm{M} \mathrm{Na}_{2} \mathrm{SO}_{4}$ at BDDP-printed electrode $\left(\mathrm{PES} / \mathrm{BDDP}=2.0\right.$ ) at (a) 50, (b) 100 and (c) $200 \mathrm{mV} \mathrm{s}^{-1}$. 